\title{
Evolution of the 2006-2007 El Niño: the role of intraseasonal to interannual time scale dynamics
}

\author{
M. J. McPhaden \\ NOAA/Pacific Marine Environmental Laboratory, Seattle, Washington, USA
}

Received: 27 September 2007 - Revised: 19 November 2007 - Accepted: 19 November 2007 - Published: 10 April 2008

\begin{abstract}
We describe development of the 2006-2007 El Niño, which started late, ended early and was below average strength. Emphasis is on the interplay between large scale, low frequency (i.e., seasonal-to-interannual time scale) deterministic dynamics and episodic intraseasonal wind forcing in the evolution of the event. Efforts to forecast the El Niño are reviewed, with discussion of factors affecting its predictability. Perspectives on the contemporaneous development of an Indian Ocean Dipole Zonal Mode event in 2006 and possible influences of global warming on the ENSO cycle, which exhibited unusual behavior in the first decade of the 21 st century, will also be presented.
\end{abstract}

\section{Introduction}

The El Niño-Southern Oscillation (ENSO) cycle is the most prominent year-to-year climate fluctuation on Earth. It originates in the tropical Pacific with unusually warm (El Niño) and cold (La Niña) events recurring approximately every $3-$ 7 yr. El Niño and La Niña events develop in association with swings in atmospheric pressure between the Australien-East Asian region and the eastern tropical Pacific. These pressure swings, known as the Southern Oscillation, are intimately related to the strength of the Pacific trade winds. ENSO extends its reach beyond the tropical Pacific through atmospheric teleconnections that can affect patterns of weather variability worldwide. ENSO's social and economic consequences, as well as its influence on marine and terrestrial ecosystems, have motivated systematic seasonal climate forecasting efforts in order to mitigate adverse impacts and/or take advantage of opportunities created by both warm and cold events (McPhaden et al., 2006a).

Correspondence to: M. J. McPhaden

(michael.j.mcphaden@noaa.gov)
In this article, we describe the evolution of El Niño conditions that developed in the tropical Pacific during 2006-2007. Our motivation is to shed light on the unusual characteristics of this event and potential reasons for its peculiar development. This El Niño started late, ended early and was below average strength. Its climate impacts were muted, with a few notable exceptions. For instance, El Niño-related drought in Indonesia contributed to a flare up of wild fires that blanketed the surrounding region in haze and smog. Pre-existing dry conditions were exacerbated in parts of Australia, resulting in significant reductions in agricultural production. Farther afield, the El Niño was probably responsible for a reduction in the number and intensity of 2006 Atlantic hurricanes relative to forecasts that called for a more active than normal hurricane season (Arguez et al., 2007). However, other expected impacts (e.g. on North American winter temperatures and precipitation, South American rainfall, Peruvian anchovy fishery, etc.) were notably absent or obscured by other influences (e.g., Hoerling et al., 2007; Arguez et al., 2007).

Our description will focus on the interplay between large scale, low frequency (i.e., seasonal-to-interannual time scale) deterministic dynamics and high frequency (intraseasonal) episodic wind forcing in the evolution of the 2006-2007 El Niño. The low frequency deterministic dynamics that we invoke derive from delayed oscillator (Battisti, 1988; Schopf and Suarez, 1988) and recharge oscillator (Jin, 1997) theories, which involve coupled ocean-atmosphere interactions and large scale ocean processes on seasonal and longer time scales. High frequency forcing occurs in the form of westerly wind bursts (Vecchi and Harrison, 2000), a significant percentage of which are associated with the intraseasonal (3090 period) Madden-Julian Oscillation (MJO; Zhang, 2005; Seiki and Takayabu, 2007). From the perspective of ENSO, westerly wind bursts are largely stochastic in nature because they are related to short-term weather variations whose predictability individually is typically limited to about two

Published by Copernicus Publications on behalf of the European Geosciences Union. 

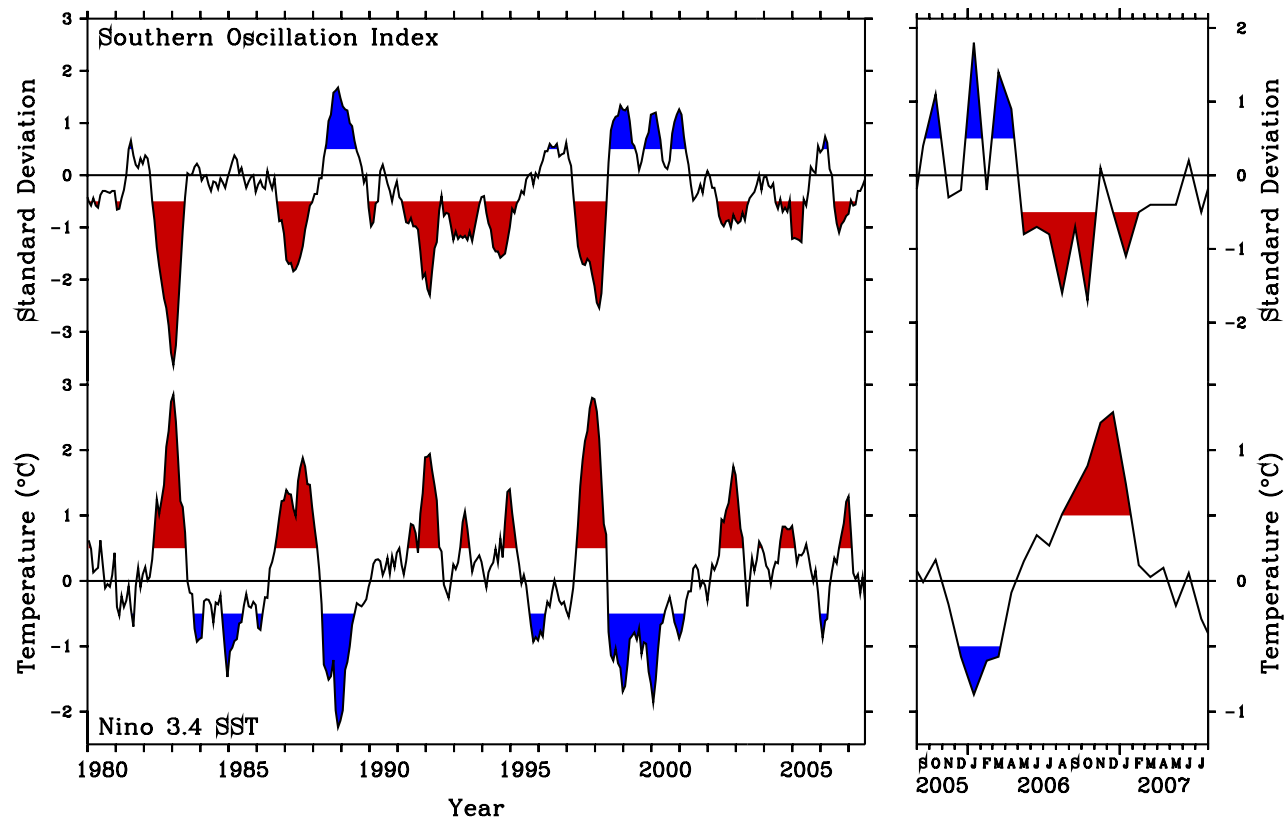

Fig. 1. The Southern Oscillation index (SOI) and Niño-3.4 SST index for January 1980 to July 2007. This plot illustrates the coupled interactions between the ocean and the atmosphere that give rise to ENSO variations. Low SOI values are associated with weaker trade winds and warm sea temperatures (El Niño), whereas high SOI values are associated with stronger trade winds and cold sea temperatures (La Niña). The NINO3.4 index is computed from monthly SST anomalies in the region $5^{\circ} \mathrm{N}-5^{\circ} \mathrm{S}, 120^{\circ}-170^{\circ} \mathrm{W}$. Positive anomalies $>0.5^{\circ} \mathrm{C}$ indicate El Niño events and negative anomalies $<-0.5^{\circ} \mathrm{C}$ indicate La Niña events. Periods of SOI greater in magnitude than 0.5 are shaded to emphasize the relationship with El Niño and La Niña. In the left panel, monthly values have been smoothed with a 5-month running mean for clarity. The right panel shows the last 2 years of the record (unsmoothed) to highlight the 2006-2007 El Niño. Note the different scales for NINO3.4 SST and SOI in the two panels.

2006-07 vs. Past El Niños

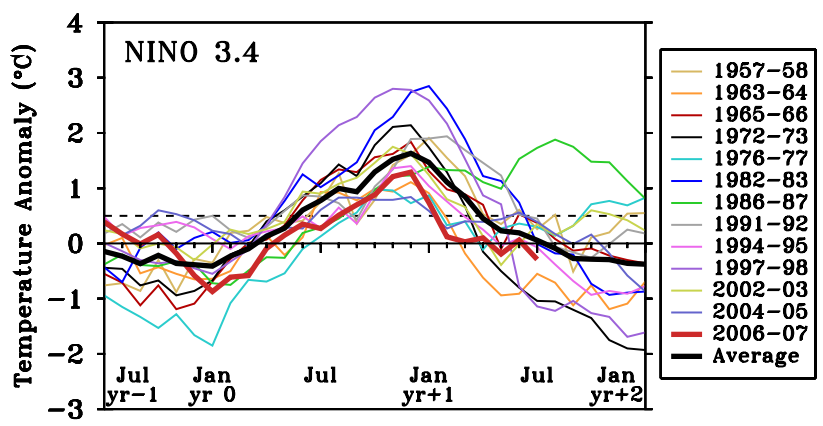

Fig. 2. NINO3.4 Index for El Niño events since 1957-1958 to 2006-2007. Time series are split into 2.5 year segments starting July the year before the peak warm anomaly (Jul yr-1) and ending January approximately one year after the peak anomaly (Jan yr+2). Dashed horizontal line indicates the $0.5^{\circ} \mathrm{C}$ threshold for the definition of El Niño warm anomalies. The thick black line is the average NINO3.4 anomaly based on the twelve previous El Niños from 1957-1958 to 2004-2005.

weeks. The precise role of this high frequency forcing depends on the stability of the coupled ocean-atmosphere system (Fedorov and Philander, 2000) but in general it introduces irregularity and limits the predictability of ENSO.
Moreover, underlying SST anomalies modulate the seasonally averaged statistics of intraseasonal variability, causing ENSO variations to be more energetic and, in some models, less predictable than if the high frequency forcing were purely random (Eisenman et al., 2005; Jin et al., 2007).

Previous modeling and observational studies have shown that intraseasonal atmospheric forcing plays a major role in development of ENSO events (Kessler et al., 1995; Kessler and Kleeman, 2000; McPhaden, 1999, 2004; Lengaigne et al., 2004; Zavala-Garay et al., 2005; Vecchi et al., 2006; McPhaden et al., 2006b; Hendon et al., 2007). McPhaden et al. (2006b) for instance found that between 1980-2005, the MJO accounted for as much variance in ENSO SST anomalies as low frequency large scale dynamical processes. The present study extends previous analyses to examine how high frequency intraseasonal forcing and deterministic low frequency dynamics contributed to development of the 20062007 El Niño. Efforts to forecast the event, which met with limited success, will be reviewed in light of the observed variability. Perspectives on the contemporaneous development of an Indian Ocean Dipole Zonal Mode event in 2006 will also be presented. Finally, this 2006-2007 El Niño was the third since 2002, representing an unusually high recurrence rate of one ENSO warm event every other year. Possible reasons this unusual behavior will be discussed. 


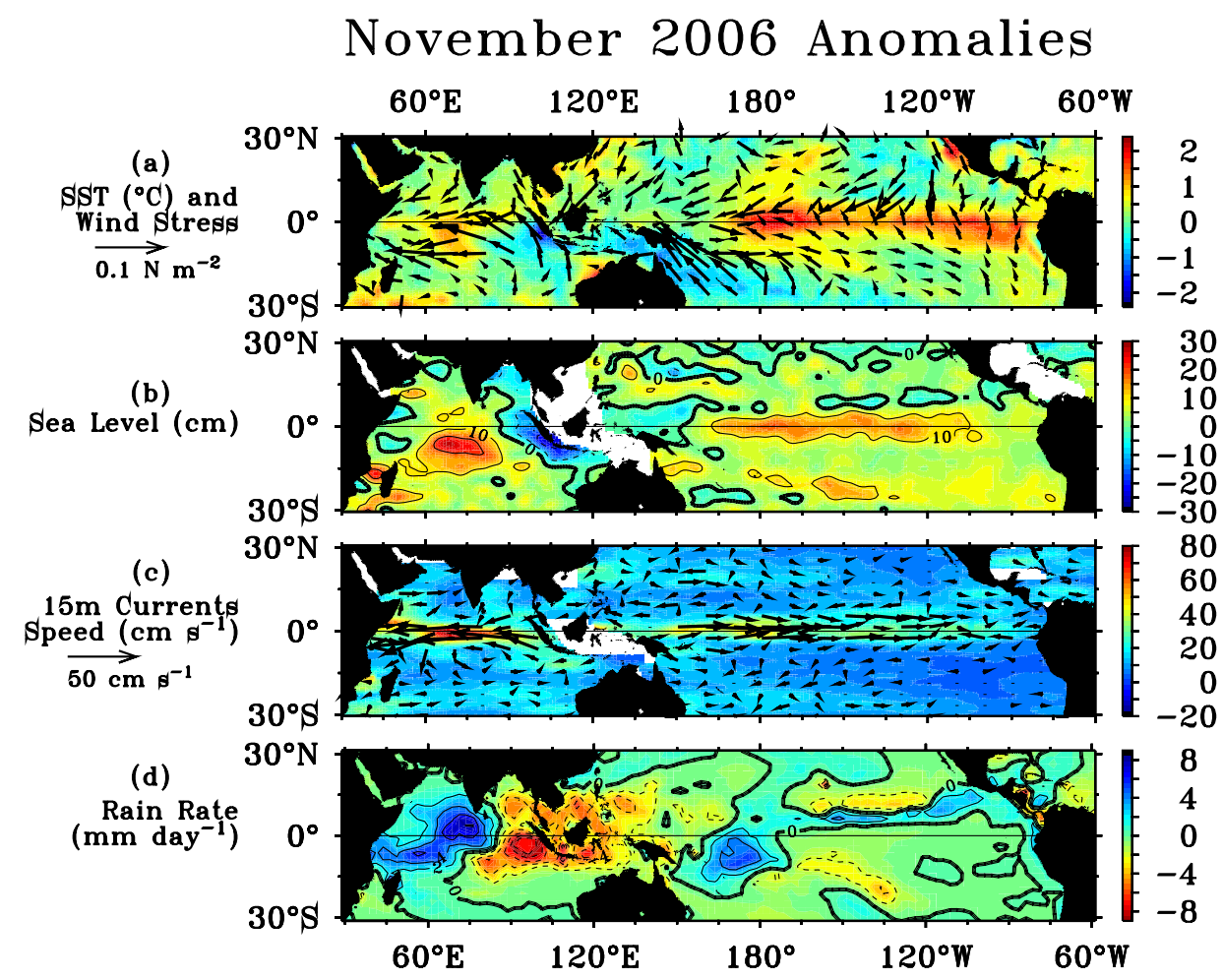

Fig. 3. Monthly anomalies from the mean seasonal cycle in November 2006 for (a) SST (based on Reynolds et al., 2002) and QuikSCAT wind stress (http://www.ifremer.fr/cersat/); (b) Jason satellite altimeter sea level anomalies; (c) current velocity (vectors) and speeds (color shading) representative of flow at $15 \mathrm{~m}$ depth in the surface mixed layer (Bonjean and Lagerloef, 2002); (d) rainrate from an analysis of satellite and in situ raingauge data (Janowiak and Xie, 1999).

\section{Temporal evolution and spatial structures}

Some basic features of the 2006-2007 El Niño are shown in the NINO3.4 and Southern Oscillation Index (SOI) time series, which are standard indices used to characterize ENSO variability (Fig. 1). The SOI, computed as a normalized pressure difference between Tahiti, French Polynesia and Darwin, Australia, is a measure of the strength of the trade winds. NINO3.4 measures of the intensity of sea surface temperature (SST) anomalies in the central Pacific, a region where the overlying atmosphere is particularly sensitive to thermal forcing from the ocean surface. These two indices are almost perfectly anti-correlated with one another, with low SOI values (weak trades) corresponding to anomalously warm SSTs, and vice versa. The tight relationship between these two indices reflects the positive feedbacks between the ocean and the atmosphere that give rise to ENSO variations.

According to the NINO3.4 and SOI indices, conditions in the tropical Pacific were distinctly La Niña-like at the start of 2006 (Fig. 1). However, these conditions soon dissipated, yielding to low SOI values and high NINO3.4 SSTs in mid-2006. The NINO3.4 index crossed the $+0.5^{\circ} \mathrm{C}$ threshold typically considered a minimum for El Niño in August 2006, peaked at $1.2-1.3^{\circ} \mathrm{C}$ in November-December 2006, then rapidly declined to zero in February 2007.
El Niño SST anomalies tend to be "phase locked" to the seasonal cycle, with peak development around the end of the calendar year. The 2006-2007 El Niño was no exception, although peak NINO3.4 anomalies were about $0.3^{\circ} \mathrm{C}$ below the average of the previous 12 El Niños from 1957-58 to 2004-05 (Fig. 2). The 2006-2007 El Niño was also shorter in duration compared to El Niños of the past 50 years, starting two months later than usual and finishing three months earlier than usual (Fig. 2).

The spatial structure of anomalies near the height of the event in November 2006 illustrates features typical of El Niño (Fig. 3; the Indian Ocean anomalies in this graphic will be discussed in later sections). Unusually warm SSTs were evident along the equator from near the coast of South America to $170^{\circ} \mathrm{E}$ (Fig. 3a), while anomalous westerly wind stress within $5^{\circ}$ of the equator west of the date line reflected a relaxation of the trades in that region. Relaxation of the trade winds resulted in higher than normal sea levels by about $10 \mathrm{~cm}$ along the equator in the eastern and central Pacific, roughly coincident with the area of warm SSTs (Fig. 3b). Elevated sea levels in the tropical Pacific correspond to a deeper than normal thermocline, the latter of which facilitates development of El Niño SST anomalies because upwelling in the equatorial cold tongue brings anomalously warm water to the surface when the thermocline is depressed (Wang and 


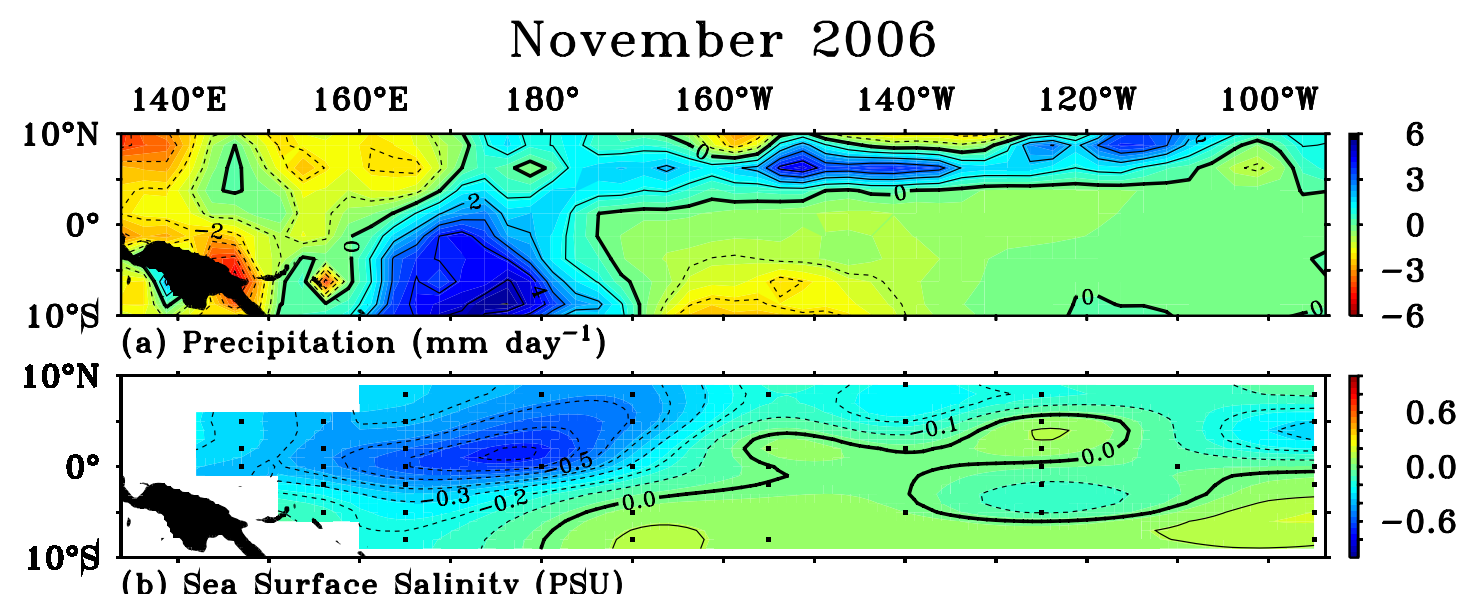

Fig. 4. Monthly anomalies of (a) rainrate and (b) sea surface salinity for November 2006. Rainrate anomalies are from Janowiak and Xie (1999) while the surface salinity anomalies are based on an objective analysis of TAO/TRITON moored time series data (McPhaden et al., 2001). Black squares in (b) indicate the location of data used in the analysis.

McPhaden, 2000). Zonal currents in the surface mixed layer (Fig. 3c) were anomalously eastward between $150^{\circ} \mathrm{E}$ and $120^{\circ} \mathrm{W}$, with speeds in excess of $40 \mathrm{~cm} \mathrm{~s}^{-1}$ west of the date line. These anomalous wind-driven currents contributed to the development of warm SST anomalies via zonal advection, particularly near the date line where they displaced the western Pacific warm pool (defined as surface waters $\geq 29^{\circ} \mathrm{C}$ ) eastward.

The pattern of anomalous convective rainfall near the equator reflects an eastward migration of the ascending branch of the Walker circulation bringing unusually heavy rains near the date line and anomalously dry conditions over Indonesia and Northern Australia (Fig. 3d). Likewise, an equatorward movement of the Intertropical Convergence Zone (ITCZ) is evident east of the date line. These shifts in rainfall patterns are a response to thermal forcing of the atmosphere by unusually warm underlying SSTs that developed near the equator in the eastern and central Pacific (Fig. 3a). Heavy rains in turn lead to significant surface freshening near the date line and in the vicinity of the ITCZ (Fig. 4) as captured by a basin scale network of salinity sensors installed in 2006 on moorings of the Tropical Atmosphere Ocean/Triangle Trans-Ocean Buoy Network (TAO/TRITON) array. Eastward advection of fresh water from the western Pacific also contributes substantially to freshening near the dateline during El Niño (e.g. Delcroix and Picaut, 1998).

\section{Intraseasonal to interannual time scales dynamics}

To characterize the large-scale low frequency dynamics associated with ENSO, we invoke the recharge oscillator theory of Jin (1997). This theory asserts that a build up of excess upper ocean heat content along equator is a necessary precondi- tion for El Niño to occur; that El Niño purges this excess heat to higher latitudes, which terminates the event; and that the time between El Niños is determined by the time it takes the equatorial Pacific to recharge with excess heat. As in the delayed oscillator theory for ENSO (Battisti, 1988; Schopf and Suarez, 1988), wind forced equatorial waves are presumed to be the primary oceanic mechanism by which these changes in upper ocean heat content occur.

As an index of upper ocean heat content, we use Warm Water Volume (WWV), which is the volume of water above the $20^{\circ} \mathrm{C}$ isotherm between $5^{\circ} \mathrm{N}$ and $5^{\circ} \mathrm{S}, 80^{\circ} \mathrm{W}$ and $120^{\circ} \mathrm{E}$ (Meinen and McPhaden, 2000). This index illustrates the basic features of recharge oscillator theory, with WWV typically leading NINO3.4 by 1-3 seasons over the period 19802007 (Fig. 5). The lead-lag relationship of these two variables also highlights the role of upper ocean heat content as the source of predictability for ENSO (Latif et al., 1998). It is noteworthy that elevated WWV is by itself not sufficient to guarantee the onset of an $\mathrm{El} \mathrm{Niño,} \mathrm{since} \mathrm{in} \mathrm{some} \mathrm{years}$ (e.g. 1989-1990) WWV was elevated but an El Niño did not occur.

For 2005-2007, WWV led NINO3.4 by $2-4$ months (Fig. 5, right panel). The heat deficit preceding La Niñalike conditions in early 2006 however was weak and therefore insufficient to support a significant cold event. Excess WWV subsequently accumulated near the equator, peaking in boreal summer 2006 prior to the onset of warm NINO3.4 SST anomalies. These positive WWV anomalies, moderate in magnitude by historical standards, presaged the later development of unusually warm SSTs associated with the 2006-2007 El Niño.

Relaxation of the trade winds during El Niño is generally not a gradual process, but one punctuated by relatively short 1-3 week episodes of strong anomalous westerly winds. Time series from the TAO/TRITON mooring array illustrate 


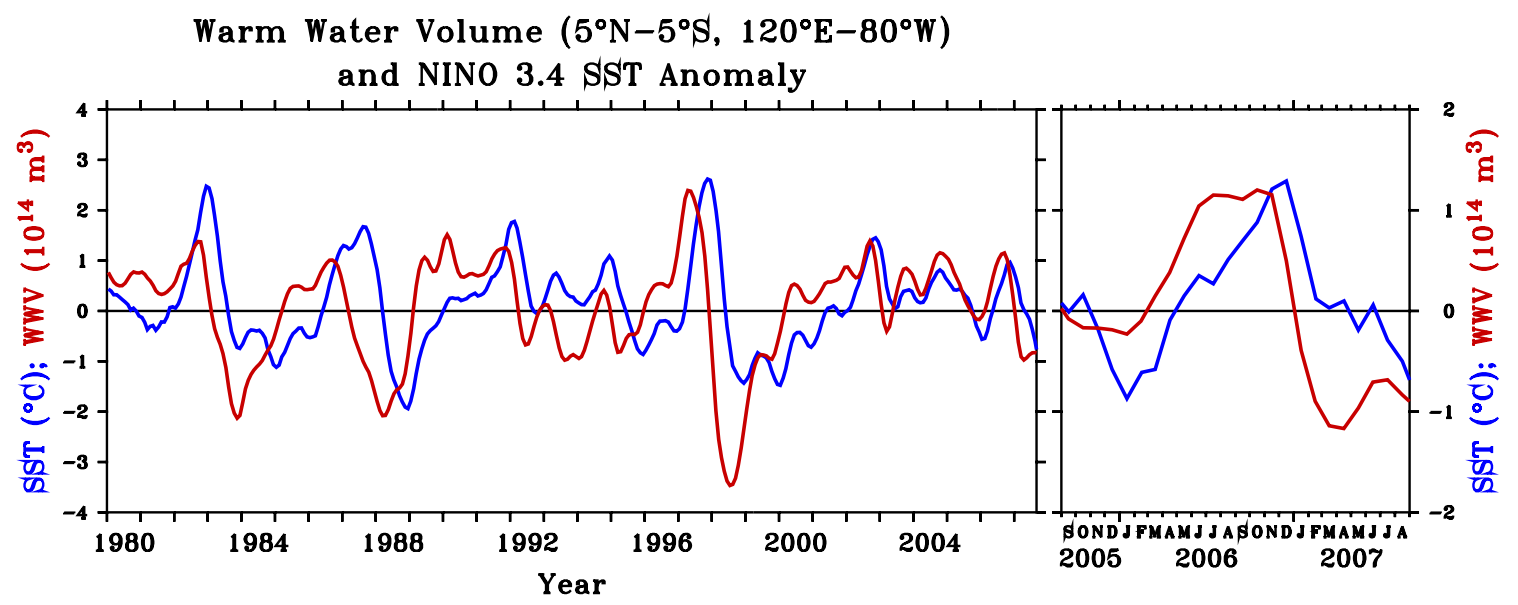

Fig. 5. Warm Water Volume (WWV) and NINO3.4 SST anomalies for 1980 to 2007 . Monthly values in left panel have been smoothed with a 5-month running mean. The right panel shows the last 2 years of the record (unsmoothed) to highlight developing El Niño conditions in late 2006. Note the different scales for WWV and NINO3.4 SST in the two panels.

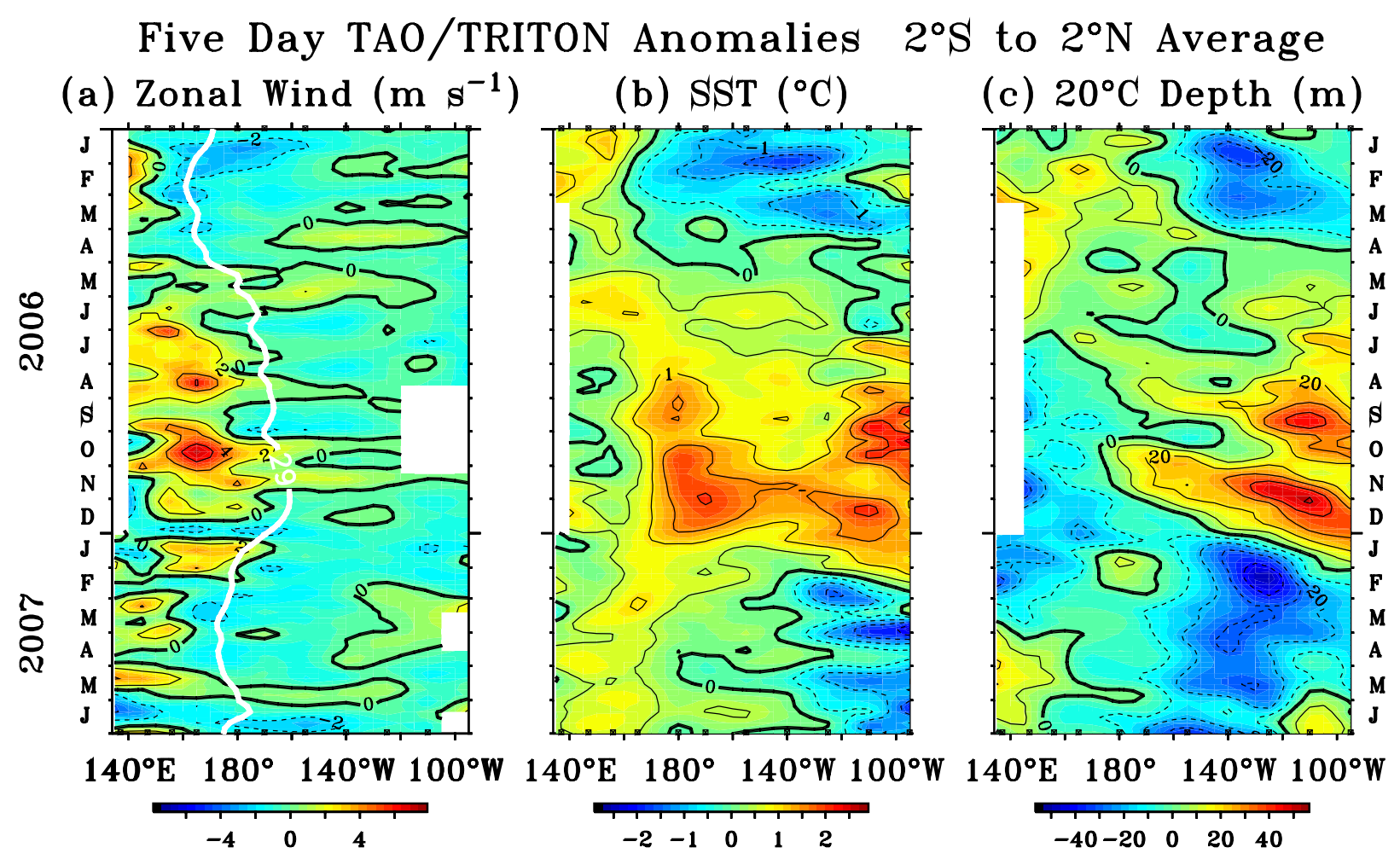

Fig. 6. Five-day average anomalies of (a) zonal wind, (b) SST, and (c) $20^{\circ} \mathrm{C}$ depth (an index for the depth of the thermocline) relative to the mean seasonal cycle from January 2006 to June 2007. The gridded analyses are based on averaged TAO/TRITON moored time series data between $2^{\circ} \mathrm{N}-2^{\circ} \mathrm{S}$. Ticks on the top (bottom) axes indicate longitudes where data were available at the start (end) of record. Solid white line in (a) is the $29^{\circ} \mathrm{C}$ isotherm which represents the eastern edge of the western Pacific warm pool.

the influence of this high frequency atmospheric wind forcing on the development of the 2006-2007 El Niño (Fig. 6). La Niña-like conditions prevailed in early 2006 with cooler than normal SSTs in the eastern Pacific, stronger than normal trade winds in the western Pacific, and a thermocline (as in- dicated by the depth of the $20^{\circ} \mathrm{C}$ isotherm) that sloped more steeply downward to the west. Further development of La Niña conditions was arrested however by the occurrence of weak westerly wind anomalies in March-May 2006. Then, against a background of elevated WWV volume, three more 


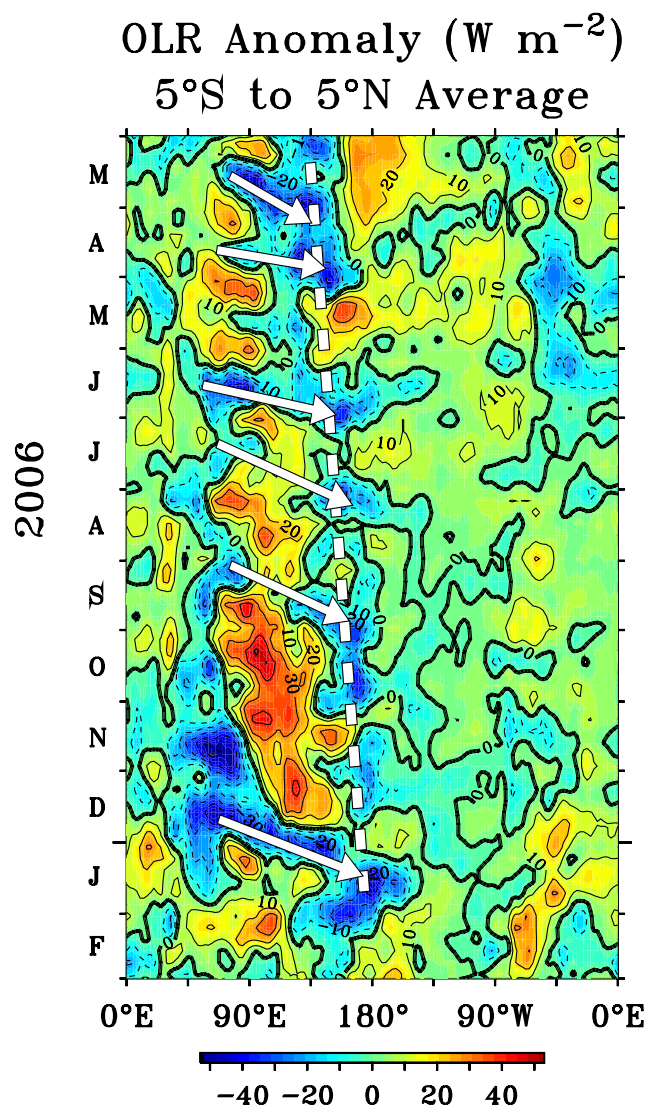

Fig. 7. Five-day Outgoing Longwave Radiation (OLR) anomalies relative to the mean seasonal cycle averaged over $5^{\circ} \mathrm{N}-5^{\circ} \mathrm{S}$ around the globe. Negative values represent anomalously high cloudiness and rainfall associated with disturbed weather conditions, while positive values represent clearer skies and generally drier conditions. The dashed white line traces the slow eastward migration deep convection in tandem with the eastward expansion of the western Pacific warm pool (Fig. 6). White arrows indicate intraseasonal eastward-propagating convective events originating over the Indian Ocean in association with active phases of the Madden-Julian Oscillation. These convective events are characterized by surface westerly winds, which once they reach the western Pacific, influence the evolution of El Niño. The Indian and Pacific Oceans are separated by Indonesian islands between about $100^{\circ}$ and $120^{\circ} \mathrm{E}$.

energetic westerly wind bursts from June through October initiated and amplified warming along the equator in the central and eastern Pacific.

Warming in the eastern Pacific was modulated by the excitation of wind forced eastward propagating equatorial Kelvin waves (evident in the intraseasonal oscillation of the $20^{\circ} \mathrm{C}$ depth). These waves depressed the thermocline by $20-50 \mathrm{~m}$, which reduced the ability of equatorial upwelling to cool the surface. Kelvin waves were also responsible for the development of eastward current anomalies along the equator east of the region of direct wind forcing (Fig. 3c) where they contributed to surface warming via zonal advection. In the region of direct wind forcing near the date line, zonal currents advected the western Pacific warm pool eastward, as indicated by the eastward migration of the $29^{\circ} \mathrm{C}$ isotherm (Fig. 6a), producing warm SST anomalies in the central Pacific. West of the date line, the sea surface cooled, in part due to intensified evaporative heat fluxes associated with the elevated local wind speeds (Fig. 6a, b). The effect of these SST changes was to shift the locus of warmest surface water eastward along the equator creating conditions favorable for an eastward migration of deep convection and heavy rainfall associated with the ascending branch of the Walker circulation (Fig. 3d).

The eastward shift in convection was, like the relaxation of the trade winds, punctuated by considerable intraseasonal variability, some of which originated over the Indian Ocean in the form of the eastward propagating MJO (Fig. 7). Month-to-month variability in the unsmoothed SOI (Fig. 1, right panel) reflects in part these intraseasonal fluctuations. Also, westerly wind bursts beginning in late June, August and October (Fig. 6) can be linked to MJO convective flare ups that developed over the Indian Ocean in early June, July and early September, respectively.

Demise of the El Niño was rapid and sudden, with anomalously cold surface water appearing along the equator in the eastern Pacific in mid-February 2007 (Fig. 6b). Termination was mediated by the eastward progression of an upwelling Kelvin wave that lifted the thermocline close enough to the surface to initiate cooling. As in previous El Niños, this upwelling Kelvin wave resulted from a combination of trade wind strengthening in the western Pacific (which occurred in late December 2006) and equatorial wave reflections at the western boundary consistent with delayed oscillator theory (e.g. Harrison and Vecchi, 1999; McPhaden and Yu, 1999; Boulanger et al., 2003). A preliminary assessment of the wind forced and western boundary generated Kelvin wave amplitudes using the model of McPhaden and Yu (1999) suggests that the directly wind forced Kelvin wave was larger. The dramatic drop in WWV in late 2006 (Fig. 5) reflects the integrated basin scale effect of these equatorial wave processes on thermocline shoaling at the end of the event (Fig. 6c).

It is noteworthy that the easterly wind anomalies in the western Pacific that contributed to the sudden demise of the El Niño were associated with the most energetic MJO event during the period March 2006-February 2007 (Fig. 7). The onset of convection associated with this MJO event occurred in mid-December over the Indian Ocean and propagated eastward into the western Pacific. Both surface easterly wind anomalies to the east of the convection and westerlies to the west of the convection were associated with this event (Fig. 8). Easterly anomalies are usually not as strong as westerly anomalies related to MJO convection in the western Pacific (Zhang and McPhaden, 2000; Seiki and Takayabu, 2007). However, Takayabu et al. (1999) also identified significant surface easterlies associated with an MJO event that 


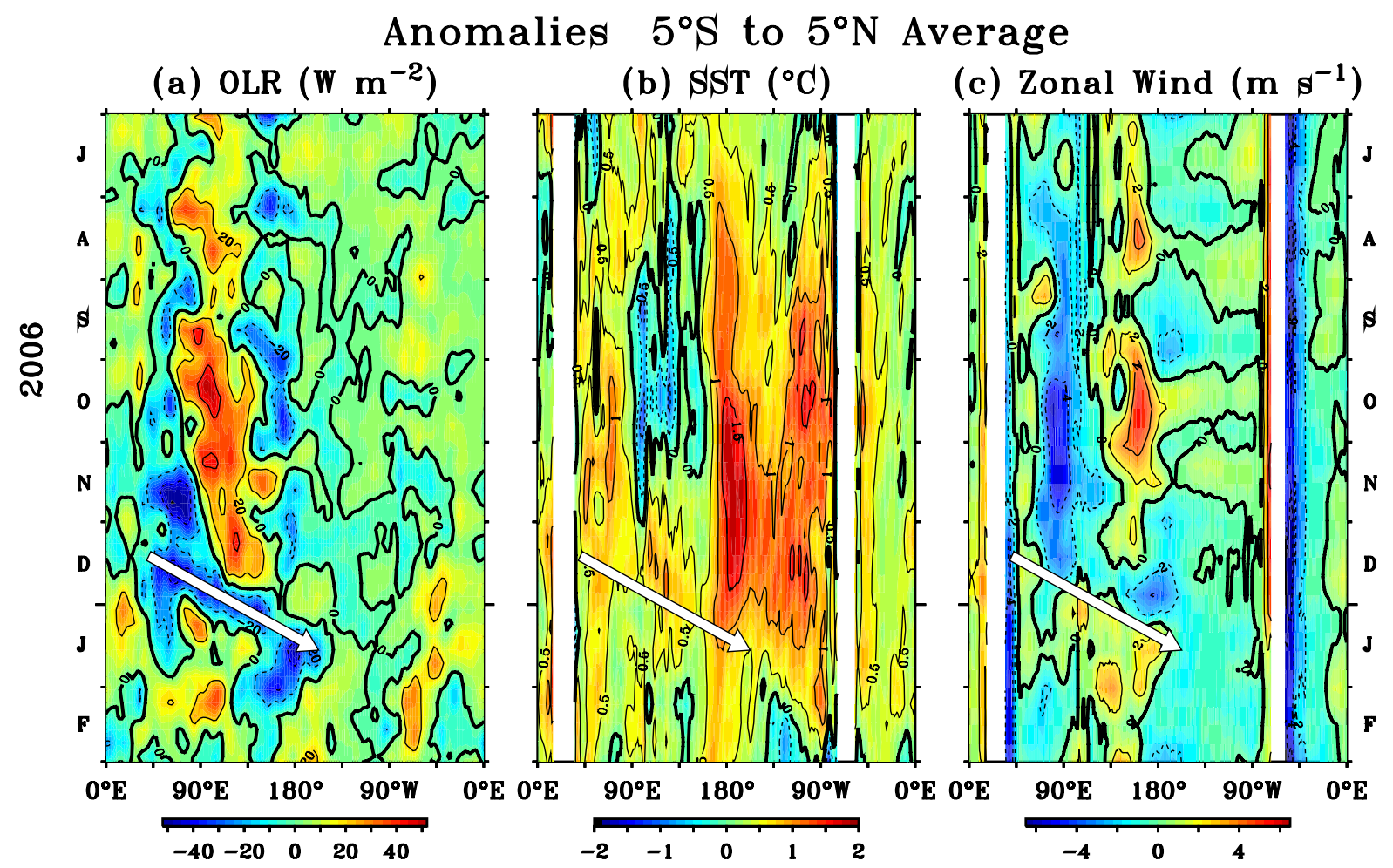

Fig. 8. Time longitude plots of (a) OLR, (b) SST and (c) zonal wind anomalies relative to the mean seasonal cycle between $5^{\circ} \mathrm{N}$ and $5^{\circ} \mathrm{S}$. Arrow in (a) indicates the propagation of the December MJO event from the Indian Ocean into the western Pacific. The arrow is repeated in (b) and (c) to show the relationship between MJO-related convection to SST and surface winds. OLR values are 5-day averages whereas the Reynolds SSTs and QuikSCAT winds are weekly.

triggered the abrupt end to the 1997-1998 El Niño in May 1998.

Anomalous easterlies often appear in the western Pacific at the height of El Niño and contribute to its termination. Except in the case of Takayabu et al. (1999) though, most interpretations of these easterlies do not invoke intraseasonal MJO dynamics. Instead, they generally emphasize longer seasonal time scale processes involving ocean-atmosphere interactions in the western Pacific (Weisberg and Wang, 1997), phase locking of zonal wind anomalies to the seasonal cycle (Harrison and Vecchi, 1999; Lengaigne et al., 2006), or seasonal shifts in the Walker circulation influenced by El Niño-induced Indian Ocean warming (Kug et al., 2005). Some or all of these processes may have been at work in late 2006 and early 2007. However, it is the abrupt appearance of these easterlies, and their relationship to MJO convection, that stands out in our data.

It is also noteworthy that the December MJO developed in the wake of the 2006 Indian Ocean Dipole Zonal Mode (IODZM) event (Figs. 3 and 8; see also Vinayachandran et al. 2007), which is an El Niño-like phenomenon in the tropical Indian Ocean (Webster et al., 1999; Saji et al., 1999). For a positive IODZM event, SST is unusually cold off the coast of Java and Sumatra and warm in the central and western equatorial Indian Ocean. Anomalous easterlies prevail along the equator, sea levels are high in the west and low in the east, and convection is enhanced (suppressed) over the warm (cold) SST anomalies. These conditions were evident in the Indian Ocean coincident with the peak phase of the El Niño in November 2006 (Fig. 3). Suppressed convection associated with cold waters in the eastern Indian Ocean can also be seen centered around $90^{\circ}-100^{\circ} \mathrm{E}$ from mid-September to November 2006 (Figs. 7 and 8). These cold, dry conditions in the eastern Indian Ocean appear to be associated with a weakening of intraseasonal variability in MJO-related convection (Shinoda and Han, 2005), which may have affected the intensity of westerly wind burst forcing in the western Pacific at the peak of the El Niño. Similarly, termination of the IODZM was linked primarily to warming off Java and Sumatra, with relatively little change in SSTs further to the west. As a result, SSTs were elevated across the entire basin in December 2006, creating conditions favorable for development of a major MJO event that contributed to the sudden end of the El Niño in February 2007. 


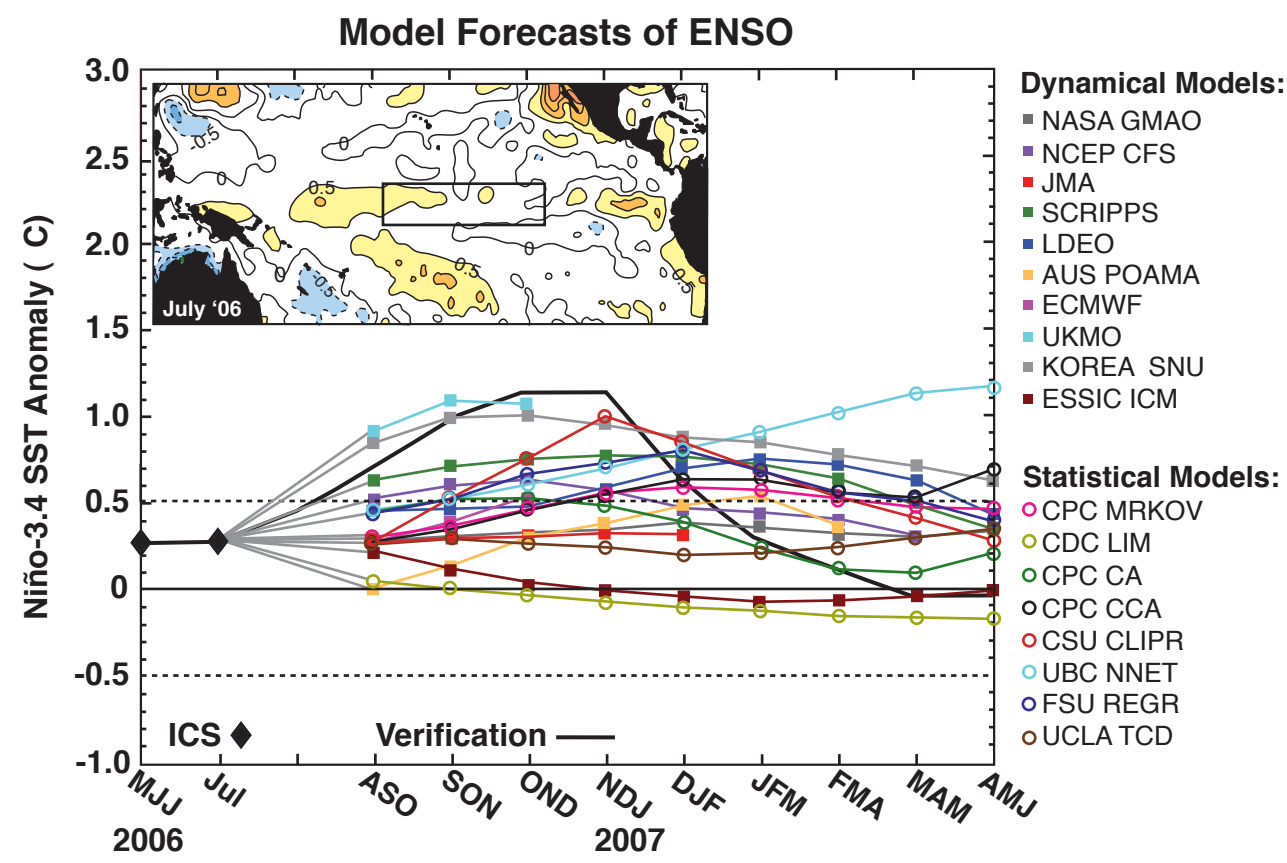

Fig. 9. Statistical and dynamical model forecasts for SST in the NINO3.4 region $\left(5^{\circ} \mathrm{N}-5^{\circ} \mathrm{S}, 120^{\circ}-170^{\circ} \mathrm{W}\right)$. Forecasts in most cases are from July 2006 initial conditions and are for seasonal averages from August-September-October (ASO) 2006 through April-May-June (AMJ) 2007. Most models predicted either neutral or warm $\left(>0.5^{\circ} \mathrm{C}\right)$ anomalies, indicating the likelihood of a weak to moderate strength El Niño lasting into boreal spring 2007. The forecasts represent ensemble means or, for most statistical models, a single deterministic forecast. Area between the dashed lines at $\pm 0.5^{\circ} \mathrm{C}$ indicates neutral conditions. Observed initial conditions (ICS) in the NINO3.4 region for May-June-July (MJJ) 2006 and in July 2006 alone are shown as black diamonds; solid black line shows forecast verification in terms of subsequent observed seasonal averages. The inset shows observed SST anomalies averaged over 9 July-5 August 2006, with the NINO3.4 region outlined. Contour interval in the inset is $0.5^{\circ} \mathrm{C}$, with warm anomalies in yellow to red colors and cold anomalies in blue. Institutions involved in issuing the forecasts are indicated by different symbols and listed at right. (Figure adapted from http://iri.columbia.edu/climate/ENSO/ currentinfo/SST_table.html, which provides a description of the various models and the methods by which the forecasts are compiled.)

\section{Forecasting the 2006-2007 El Niño}

Except for the regular progression of the seasons, ENSO is the most predictable climate fluctuation on the planet. Efforts to forecast ENSO SST variations in the tropical Pacific and the their impacts on climate date back to the mid1980s (Cane et al., 1986; Barnett et al., 1988). The efforts have been motivated by the realization that ENSO's widespread socio-economic impacts create a demand for accurate, timely, and detailed forecast guidance for practical applications in many parts of the globe. At present, there are about 20 institutions worldwide that routinely issue ENSO forecasts using numerical methods that range from statistical to fully coupled ocean-atmosphere general circulation model (http://iri.columbia.edu/). Model predictability studies suggest that ENSO forecast skill should extend to lead times of about one year, but progress has been slow in predicting the onset, ultimate magnitude, and demise of ENSO events with uniform reliability (e.g. Barnston et al., 1999; McPhaden et al., 2006a). Intraseasonal atmospheric variability is one of several factors, along with numerical model biases and errors in initial conditions, which limit the skill of ENSO forecasts.
Below we illustrate some of the challenges in ENSO prediction highlighting advisories issued by NOAA's National Centers for Environmental Prediction (NCEP) for the 2006-2007 El Niño. We focus on NOAA/NCEP because their forecast advisories are representative of others, are based on both statistical models and dynamical coupled ocean-atmosphere models, are regularly published on the World Wide Web (http://www.cpc.ncep.noaa.gov/products/ analysis_monitoring/enso_advisory/index.shtml), and are widely cited. Our emphasis is likewise on forecasting tropical Pacific SSTs associated with El Niño rather than the more complicated problem of forecasting El Niño impacts.

On 9 March 2006, following several months of below normal WWV anomalies and NINO3.4 SSTs (Figs. 1, 5, and 6b), NCEP issued an advisory that read, "La Niña conditions are expected to continue during the next 3-6 months." This advisory was followed almost immediately by an unexpected weakening of the trade winds. By June 2006, three months after the March advisory was issued, near normal SSTs rather than the predicted below normal temperatures prevailed across the Pacific. 
NCEP advisories in early June and July stated that, "ENSO-neutral conditions are expected to prevail during the next 3 months." However, a westerly wind burst occurred in late June and early July, followed in mid-July by a sharp rise in SST anomalies along the equator in the central and eastern Pacific (Figs. 6). It was after the appearance of this windinduced basin scale anomalous warming, which exceeded $1^{\circ} \mathrm{C}$ east of $120^{\circ} \mathrm{W}$, that NCEP issued its first advisory of the year (on 10 August 2006) indicating the possible development of El Niño: "ENSO-neutral conditions are expected to continue for the next one to three months, with a $50 \%$ chance that weak El Niño conditions will develop by the end of 2006." This advisory also highlighted elevated heat content along the equator (Fig. 5) as a potential precursor of continued warming. Models from several other institutions also predicted the development of warm anomalies over the next 1-3 seasons, though some of the predicted anomalies were below the $0.5^{\circ} \mathrm{C}$ threshold necessary to qualify as "El Niño" (Fig. 9). The tentative wording of the NCEP advisory was thus echoed in other advisories issued at the time. However, unexpected energetic westerly wind bursts later in August and October accelerated the SST warming to levels that were in most cases higher than expected based on predictions from July initial conditions (Fig. 9).

On 7 December 2007 at the height of the El Niño, NCEP's advisory read, "El Niño conditions are likely to continue through May 2007.” Prevailing conditions at the time seemed favorable for this happen: SSTs were at their peak, WWV was high, and the trade winds were still anomalously weak. However, the sudden development of easterly anomalies in late December and a rapidly shoaling thermocline in the east brought the event to an abrupt end by mid-February, three months earlier than predicted.

In summary, state-of-the-art climate forecast models met with only limited success in forecasting the onset, ultimate amplitude, and demise of the 2006-2007 El Niño at lead times of 1-3 seasons. Calendar year 2006 started with forecasts calling for La Niña rather than El Niño, followed by forecasts for ENSO neutral conditions. A moderate build up of heat content in boreal spring and summer 2006 provided some predictability for warming later in the year. However, advisories predicting El Niño were issued only after initial basin scale warming appeared in mid-year and then the event developed more rapidly than expected. Finally, forecast models did not foresee the early and rapid demise of the El Niño from peak conditions in late 2006.

Episodic wind forcing was one confounding factor that affected the predictions consistent with previous empirical, modeling, and theoretical studies on the role of intraseasonal variability in the ENSO cycle (Moore and Kleeman, 1999; Kessler and Kleeman, 2000; Takyabu et al., 2001; McPhaden et al., 2006b). Observations during 2006-2007 were also consistent with recent studies that emphasize the importance of "state dependent stochastic forcing," i.e. feedbacks from developing ENSO SSTs to intraseasonal wind fluctuations
(Lengaigne et al., 2004; Eisenman et al., 2005; Vecchi et al., 2006; Jin et al., 2007; Seiki and Takayabu, 2007). The most energetic westerly wind bursts coincided with the appearance of warm SST anomalies during August to October 2006, which helped to boost the amplitude of warming once it was underway (Fig. 6). Forecast models in general do not adequately represent intraseasonal atmospheric variability and thus these potential feedbacks, which may account for some of the differences between the predictions and the observations.

The limited success in forecasting the 2006-2007 El Niño is typical of that for most recent ENSO events (McPhaden et al., 2006a). Community-wide efforts are underway to improve ENSO forecast skill through development of better forecast models, improved data assimilation techniques, coupled ocean-atmosphere model initialization procedures, and sophisticated ensemble forecasting methods. The results of this analysis suggest that improvements in the representation of high frequency atmospheric variability, especially that related to the MJO, in statistical and dynamical atmospheric models may lead to improvements in ENSO forecasting. Proper accounting of this high frequency variability, including SST feedbacks on it, would increase the realism of individual model predictions as well as the realism of the ensemble spread of those predictions (e.g. Jin et al., 2007), which provides a measure of forecast uncertainty in probabilistic terms. Accurate representation oceanic and atmospheric variability in the Indian Ocean region, which is the spawning ground for the MJO, may also lead to improvements in forecast skill (e.g., Clarke and van Gorder, 2003).

\section{Discussion and conclusions}

The focus of this article has been on the interplay between large scale low frequency seasonal-to-interannual time scale dynamics and intraseasonal atmospheric forcing in the evolution of the 2006-2007 El Niño. However, it is interesting to note that this warm event was the third since 2002 with very few intervening periods of unusually cold conditions (Fig. 1). In addition, there has been a subtle change in the relationship between WWV and NINO3.4 SST since the beginning of the 21st century. Specifically, during the 1980s and 1990s, WWV lead NINO3.4 by typically 2-3 seasons whereas since 2000 the lead time appears to have shortened to only about one season (Fig. 5). Do these conditions indicate a significant change in the ENSO cycle and, if so, is that change the result of natural variability or greenhouse gas forcing?

The unusually high recurrence rate of one El Niño every other year is similar to that observed in the early to mid1990s (Fig. 1). Trenberth and Hoar (1996) argued that the cluster of 1990s warm events, and the tendency for more El Niños than La Niñas since the mid-1970s, was a response of the ENSO cycle to greenhouse gas forcing. However, other studies based on the instrumental record, paleoclimate 
analyses, and climate change models, suggest that while the ENSO cycle may undergo natural variations in strength and frequency on decadal and longer time scales, there is no conclusive evidence that it has changed significantly because of global warming (Wunsch, 1999; Tudhope et al., 2001; van Oldenborgh et al., 2005). Global change models, even though they have known flaws that compromise the reliability of detailed regional scale projections, further suggest that ENSO may not change much in response to increases in atmospheric greenhouse gas concentrations over the next 100 years (van Oldenborgh et al., 2005). Thus, although we cannot rule out the possibility that there has been an anthropogenic influence on ENSO, the evidence to date suggests that the behavior of the ENSO cycle in the first decade of the 21 st century is probably not outside the range expected for nature climate variability. Possible alternative interpretations of the observed variability include fluctuations in the ENSO cycle due to the chaotic internal dynamics of the oceanatmosphere system and/or interaction with decadal time scale phenomena such as the Pacific Decadal Oscillation (Mantua et al., 1997).

An Indian Ocean Dipole/Zonal Mode event developed coincident with the El Niño in 2006. The co-occurrence of an El Niño and an IODZM event is likely to rekindle the debate about whether the IODZM is forced from the tropical Pacific by ENSO or whether it is an independent mode of climate variability (e.g. Meyers et al., 2007). Regardless of the origins of the 2006 IODZM event though, our analysis suggests that anomalous oceanic and atmospheric conditions in the Indian Ocean during the latter half of 2006 may have significantly affected the evolution of the 2006-2007 El Niño. Specifically, a reduction in MJO convective activity over the unusually cold surface waters of the eastern Indian Ocean during mid-September to November 2006 may have affected the statistics of westerly wind burst forcing near the peak of the El Niño. Also, development of warm SST anomalies across the Indian Ocean basin in the wake of the IODZM created conditions favorable for a strong MJO outbreak that hastened the demise of the El Niño. Modeling studies indicate that the structure and magnitude of tropical Indian Ocean SST anomalies is important in determining the strength of atmospheric teleconnections from the Indian Ocean to the Pacific Ocean trade wind field on seasonal-to-interannual time scales (Annamalai et al., 2005). Our results suggest that the effectiveness of MJO forcing of ENSO variability may be likewise be modulated by Indian Ocean SSTs, a hypothesis that could explored through more systematic empirical analyses of other El Niño events and through numerical model studies.

Climate variability during 2006-2007 highlights the dilemma of defining what constitutes an El Niño. Most experts would probably agree that the unusual warming observed in the tropical Pacific from mid-2006 to early 2007 qualifies as a weak-to-moderate strength El Niño. However, in many cases populations typically affected by El Niño felt little or no impact (with a few notable exceptions as mentioned in the Introduction) probably because of the relatively short duration and below average amplitude of the event. For example, the El Niño was essentially over by the start of the January to March 2007 rainy season in Peru and Ecuador when El Niño normally has its most significant impacts on the regional climate of tropical western South America. Thus, a definition of ENSO in terms of impacts vs. central Pacific SSTs would lead to very different perspective on the significance of the 2006-2007 El Niño.

There are also indications that El Niño's climatic impacts may depend sensitively on whether anomalous SSTs in the equatorial Pacific are largest near the date line or in the cold tongue (e.g. Larkin and Harrison, 2005; Krishna-Kumar, 2006; Ashok et al., 2007). SSTs were relatively large near the date line during the peak of the event in NovemberDecember 2006 and whether anomaly structure was important in affecting El Niño's climate impacts is a matter of debate. Nonetheless, these distinctions are important because they illustrate the challenge of communicating knowledge about the ENSO cycle, both in terms of scientific advances and uncertainties, to decision makers and the general public.

Acknowledgements. The author would like to thank two reviewers and Tony Barnston for comments on an earlier version of this manuscript; and Matthieu Lengaigne for valuable discussions on ENSO dynamics. Special thanks to D. McClurg for help with graphics. This research was supported by NOAA's Climate Program Office. Publication of this paper was partially funded by the Joint Institute for the Study of the Atmosphere and Ocean (JISAO) under NOAA Cooperative Agreement No. NA17RJ1232. JISAO contribution No. 1450. PMEL publication No. 3119.

Edited by: P. Lagos

Reviewed by: T. Mitchell and K. Takahashi

\section{References}

Annamalai, H., Xie, S. P., McCreary, J. P., and Murtugudde, R.: Impact of Indian Ocean Sea Surface Temperature on Developing El Niño, J. Climate, 18, 302-319, 2005.

Arguez, A., Waple, A. M., and Sanchez-Lugo, A. M.: State of the Climate in 2006 - Supplement, B. Am. Meteorol. Soc., 88, 929 932, 2007.

Ashok, K., Behara, S. K., Rao, S. A., Weng, H., and Yamagata, T.: El Niño Modoki and it possible teleconnection, J. Geophys. Res. 112, C11007, doi:10.1029/2006JC003789, 2007.

Barnett, T. P., Graham, N., Cane, M., Zebiak, S., Dolan, S., O'Brien, J., and Legler, D.: On the prediction of the El Niño of 1986-87, Science, 241, 191-196, 1988

Barnston, A. G., He, Y., and Glantz, M. H.: Predictive skill of statistical and dynamical climate models in SST forecasts during the 1997-98 El Niño episode and the 1998 La Niña onset, B. Am. Meteorol. Soc., 80, 217-244, 1999.

Battisti, D. S.: Dynamics and thermodynamics of a warming event in a coupled atmosphere-ocean model, J. Atmos. Sci., 45, 28892919, 1988. 
Boulanger, J.-P., Cravatte, S., and Menkes, C.: Generation of interannual Kelvin waves in the western Pacific Ocean, J. Geophys. Res., 108(C10), 3311, doi: 10.1029/2002JC001760, 2003.

Bonjean, F. and Lagerloef, G. E. S.: Diagnostic Model and Analysis of the Surface Currents in the Tropical Pacific Ocean, J. Phys. Oceanogr., 32, 2938-2954, 2002.

Cane, M. A., Dolan, S. C., and Zebiak, S. E.: Experimental forecasts of the 1982/83 El Niño, Nature, 321, 827-832, 1986.

Clarke, A. J. and Van Gorder, S.: Improving El Niño prediction using a space-time integration of Indo-Pacific winds and equatorial Pacific upper ocean heat content, Geophys. Res. Lett., 30, 1399, doi:10.1029/2002GL016673, 2003.

Delcroix, T. and Picaut, J.: Zonal displacement of the western equatorial Pacific "fresh pool", J. Geophys. Res., 103, 1087-1098, 1998.

Eisenman, I., Yu, L., and Tziperman, E.: Westerly wind bursts: ENSO's tail rather than the dog?, J. Climate, 18, 5224-5238, 2005.

Fedorov, A. V. and Philander, S. G.: Is El Niño changing?, Science, 288, 1997-2001, 2000.

Harrison, D. E. and Vecchi, G. A.: On the termination of El Niño, Geophys. Res. Lett., 26, 1593-1596, 1999.

Hendon, H. H., Wheeler, M. C., and Zhang, C.: Seasonal Dependence of the MJO-ENSO Relationship, J. Climate, 20, 531-543, 2007.

Hoerling, M., Eischeid, J., Quan, X., and Xu, T.: Explaining the record US warmth in 2006, Geophys. Res. Lett., 34, L17704, doi:10.1029/2007GL030643, 2007.

Janowiak, J. E. and Xie, P.: CAMS_OPI: A Global Satellite-Rain Gauge Merged Product for Real-Time Precipitation Monitoring Applications, J. Climate, 12, 3335-3342, 1999.

Jin, F.-F.: An equatorial ocean recharge paradigm for ENSO. Part I: Conceptual model, J. Atmos. Sci., 54, 811-829, 1997.

Jin, F.-F., Lin, L., Timmermann, A., and Zhao, J.: Ensemblemean dynamics of the ENSO recharge oscillator under statedependent stochastic forcing, Geophys. Res. Lett., 34, L03807, doi:10.1029/2006GL027372, 2007.

Kessler, W. S., McPhaden, M. J., and Weickmann, K. M.: Forcing of intraseasonal Kelvin Waves in the equatorial Pacific, J. Geophys. Res., 100, 10 613-10 631, 1995.

Kessler, W. S. and Kleeman, R.: Rectification of the MaddenJulian oscillation into the ENSO cycle, J. Climate, 13, 35603575, 2000.

Kug, J., An, S., Jin, F., and Kang, I.: Preconditions for El Niño and La Niña onsets and their relation to the Indian Ocean, Geophys. Res. Lett., 32, L05706, doi:10.1029/2004GL021674, 2005.

Kumar, K. K., Rajagopalan, B., Hoerling, M., Bates, G., Cane, M. A.: Unraveling the Mystery of Indian Monsoon Failure During El Niño, Science, 314, 115-119, 2006.

Larkin, N. K. and Harrison, D. E.: On the definition of El Niño and associated seasonal average U.S. weather anomalies, Geophys. Res. Lett., 32, L13705, doi:10.1029/2005GL022738, 2005.

Latif, M., Anderson, D., Barnett, T., Cane, M., Kleeman, R., Leetmaa, A., O'Brien, J., Rosati, A., and Schneider, E.: A review of the predictability and prediction of ENSO, J. Geophys. Res., 103, 14 375-14394, 1998.

Lengaigne, M., Guilyardi, E., Boulanger, J. P., Menkes, C., Delecluse, P., Inness, P., Cole, J., and Slingo, J.: Triggering of El Niño by westerly wind events in a coupled general circulation model, Clim. Dynam., 23, 601-620, 2004.

Lengaigne, M., Boulanger, J.-P., Menkes, C., and Spencer, H.: Influence of the seasonal cycle on the termination of El Niño events ina coupled general circulation model, J. Climate, 19, 18501868, 2006.

Mantua, N. J., Hare, S. J., Zhang, Y., Wallace, J. M., and Francis, R. C.: A Pacific interdecadal oscillation with impacts on salmon production, B. Am. Meteorol. Soc., 78, 1069-1079, 1997.

McPhaden, M. J. and Yu, X.: Equatorial waves and the 1997-98 El Niño, Geophys. Res. Lett., 26, 2961-2964, 1999.

McPhaden, M. J., Delcroix, T., Hanawa, K., Kuroda, Y., Meyers, G., Picaut, J., and Swenson, M.: The El Niño/Southern Oscillation (ENSO) Observing System, in: Observing the Ocean in the 21st Century, Australian Bureau of Meteorology, Melbourne, Australia, 231-246, 2001.

McPhaden, M. J., Zebiak, S. E., and Glantz, M. H.: ENSO as an integrating concept in Earth science, Science, 314, 1740-1745, 2006a.

McPhaden, M. J., Zhang, X., Hendon, H. H., and Wheeler, M. C.: Large Scale Dynamics and MJO Forcing of ENSO Variability, Geophys. Res. Lett., 33(16), L16702, doi:10.1029/2006GL026786, 2006b.

Meinen, C. S. and McPhaden, M. J.: Observations of warm water volume changes in the equatorial Pacific and their relationship to El Niño and La Niña, J. Climate, 13, 3551-3559, 2000.

Meyers, G., McIntosh, P., Pigot, L., and Pook, M.: The Years of El Niño, La Niña, and Interactions with the Tropical Indian Ocean, J. Climate, 20, 2872-2880, 2007.

Moore, A. M. and Kleeman, R.: Stochastic forcing of ENSO by the intraseasonal oscillation, J. Climate, 12, 1199-1220, 1999.

Reynolds, R. W., Rayner, N. A., Smith, T. M., Stokes, D. C., and Wang, W. Q.: An improved in situ and satellite SST analysis for climate, J. Climate, 15, 1609-1625, 2002.

Saji, N. H., Goswami, B. N., Vinayachandran, P. N., and Yamagata, T.: A dipole mode in the tropical Indian Ocean, Nature, 401, 360-363, 1999.

Schopf, P. S. and Suarez, M. J.: Vacillations in a coupled oceanatmosphere model, J. Atmos. Sci., 45, 549-566, 1988.

Seiki, A. and Takayabu, Y. N.: Westerly wind bursts and their relationship with intraseasonal variability and ENSO. Part I: Statistics. Mon. Weather Rev., 135, 3325-3345, 2007.

Shinoda, T., and Han, W. : Influence of the Indian Ocean Dipole on Atmospheric Subseasonal Variability, J. Climate, 18, 38913909, 2005.

Takayabu, Y. N., Iguchi, T., Kachi, M., Shibata, A., and Kanzawa, H.: Abrupt termination of the 1997-98 El Niño in response to a Madden-Julian oscillation, Nature, 402, 279-282, 1999.

Trenberth, K. E. and Hoar, T. J.: The 1990-95 El Niño-Southern Oscillation event: Longest on record, Geophys. Res. Lett., 23, 57-60, 1996.

Tudhope, A. W., Chilcott, C. P., McCulloch, C. P., Cook, E. R., et al.: Variability in the El Niño-Southern Oscillation through a glacial-interglacial cycle, Science, 291, 1511-1517, 2001.

van Oldenbourgh, G. J., Philip, S. Y., and Collins, M.: El Niño in a changing climate: a multi-model study, Ocean Sci., 1, 81-95, 2005 ,

http://www.ocean-sci.net/1/81/2005/.

Vecchi, G. A. and Harrison, D. E.: Tropical Pacific sea surface temperature anomalies, El Niño, and equatorial westerly wind 
events, J. Climate, 13, 1814-1830, 2000.

Vecchi, G. A., Wittenberg, A. T., and Rosati, A.: Reassessing the role of stochastic forcing in the 1997-1998 El Niño, Geophys. Res. Lett., 33, L01706, doi:10.1029/2005GL024738, 2006.

Vinayachandran, P. N., Kurian, J., and Neema, C. P.: Indian Ocean response to anomalous conditions in 2006, Geophys. Res. Lett., 34, L15602, doi:10.1029/2007GL030194, 2007.

Wang, W. and McPhaden, M. J.: The surface layer heat balance in the equatorial Pacific Ocean, Part II: Interannual variability, J. Phys. Oceanogr., 30, 2989-3008, 2000.

Webster, P. J., Moore, A. M., Loschnigg, J. P., and Leben, R. R.: Coupled ocean-atmosphere dynamics in the Indian Ocean during 1997-98, Nature, 401, 356-360, 1999.

Weisberg, R. H. and Wang, C.: A western Pacific oscillator paradigm for the El Niño-Southern Oscillation, Geophys. Res. Lett., 24, 779-782, 1997.
Wunsch, C.: The interpretation of short climate records, with comments on the North Atlantic and Southern Oscillations, B. Am. Meteorol. Soc., 80, 245-255, 1999.

Yu, X. and McPhaden, M. J.: Seasonal variability in the equatorial Pacific, J. Phys. Oceanogr., 29, 925-947, 1999.

Zavala-Garay, J., Zhang, C., Moore, A. M., Kleeman, R.: The linear response of ENSO to the Madden-Julian Oscillation, J. Climate, 18, 2441-2459, 2005.

Zhang, C.: Madden-Julian Oscillation, Rev. Geophys., 43, RG2003, doi:10.1029/2004RG000158, 2005.

Zhang, C. and McPhaden, M. J.: Intraseasonal surface cooling in the equatorial western Pacific, J. Climate, 13, 2261-2276, 2000. 